\title{
Stabilisasi/Solidifikasi Tanah Tercemar Merkuri Tambang Emas Rakyat Kulon Progo Yogyakarta Menggunakan Campuran Semen Portland dan
}

\author{
Elok Dian Karisma Pagri Anisa dan Yulinah Trihadiningrum \\ Jurusan Teknik Lingkungan, Fakultas Teknik Sipil dan Perencanaan, Institut Teknologi Sepuluh \\ Nopember (ITS) \\ Jl. Arief Rahman Hakim, Surabaya 60111 Indonesia \\ e-mail: yulinah_t@enviro.its.ac.id
}

\begin{abstract}
Abstrak - Kegiatan tambang emas rakyat merupakan sumber antropogenik terbesar pencemaran merkuri di tanah. Hasil uji total konsentrasi (TK) merkuri pada sampel tanah dari lokasi penambangan emas Kulon Progo Yogyakarta adalah $0,89 \mathrm{mg} / \mathrm{kg}$. Hasil tersebut melebihi baku mutu TK-C merkuri menurut Lampiran V PP No. 101 Tahun 2014 tentang Pengelolaan Limbah B3 sebesar 0,30 mg/kg. Oleh karena itu, diperlukan upaya remediasi untuk meminimisasi tingkat pencemaran merkuri. Salah satu metode yang dapat diaplikasikan adalah teknik stabilisasi/solidifikasi (S/S). Penelitian ini bertujuan untuk menentukan komposisi optimum binder semen dan tras yang digunakan dalam proses $\mathrm{S} / \mathrm{S}$, serta komposisi tanah tercemar yang dapat ditambahkan ke dalam campuran semen-tras. Penelitian dilakukan dalam 2 tahap. Pada tahap I digunakan komposisi semen portland-tras dengan variasi perbandingan berat 100:0, 90:10, 80:20, 70:30, 60:40, 50:50, 40:60, 30:70, 20:80, dan 10:90. Sedangkan pada penelitian tahap II dilakukan penambahan sampel tanah tercemar ke dalam campuran optimum binder yang diperoleh dari penelitian tahap I, dengan variasi rasio berat binder : tanah 50:50, 40:60, 30:70, 20:80, dan 10:90. Pada akhir tahap dilakukan uji Toxicity Characteristic Leaching Procedure (TCLP) berdasarkan US EPA method 1311. Uji kuat tekan dilakukan terhadap benda uji S/S menggunakan Toorse Universal Testing Machine.Kadar merkuri diukur menggunakan metode spektrofotometri serapan atom menurut SNI 6989.78:2011. Dari penelitian tahap I didapatkan komposisi optimum semen-tras sebesar 10:90, dengan nilai kuat tekan 96 $\mathrm{kg} / \mathrm{cm}^{2}$. Sedangkan dari penelitian tahap II didapatkan nilai kuat tekan komposisi optimum binder : tanah 10:90 yaitu $6 \mathrm{~kg} / \mathrm{cm}^{2}$ dengan konsentrasi merkuri pada uji TCLP sebesar 0,0011 mg/L. Hasil uji kuat tekan memenuhi baku mutu menurut US EPA untuk pengelolaan tanah tercemar sebesar $3,5 \mathrm{~kg} / \mathrm{cm}^{2}$. Demikian pula hasil uji TCLP memenuhu baku mutu untuk produk hasil S/S sesuai dengan Lampiran IV PP No. 101 Tahun 2014 sebesar $0,05 \mathrm{mg} / \mathrm{L}$.
\end{abstract}

Kata Kunci-merkuri, semen portland, stabilisasi/solidifikasi, tanah, tras.

\section{PENDAHULUAN}

$\mathrm{K}$ EGIATAN tambang emas rakyat di Kulon Progo Yogyakarta dilakukan secara konvensional di lokasi terbuka menggunakan teknik amalgamasi yaitu pencampuran serbuk pasir dengan merkuri membentuk amalgam (alloy) yang digunakan sebagai pengikat emas [10]. Limbah tailing hasil aktivitas pertambangan dialirkan ke tanah serta sungai menyebabkan kontaminasi tanah dan lumpur sungai oleh merkuri. Hasil analisis gravimetri menunjukkan dalam kegiatan ini sekitar 70-80\% merkuri hilang ke dalam sedimen sungai, tailing, dan tanah [7]. Hasil penelitian sebelumnya menunjukkan tanah sekitar tambang emas rakyat Kulon Progo mengandung merkuri dengan kadar lebih dari 50 ppm [4]. Hasil tersebut jauh melebihi ambang batas menurut Peraturan Pemerintah No. 101 Tahun 2014 tentang Pengelolaan Limbah Bahan Berbahaya dan Beracun pelepasan merkuri di lingkungan sebesar $0,05 \mathrm{mg} / \mathrm{L}$ berat kering. Logam merkuri yang mencemari tanah apabila tidak dibatasi pergerakannya akan masuk ke dalam air tanah yang menjadi sumber air minum masyarakat setempat.

Logam merkuri teridentifikasi sebagai salah satu unsur dengan sifat toksisitas tinggi serta kemudahan mengalami transformasi menjadi bentuk yang lebih toksik [10]. Merkuri membahayakan kehidupan manusia melalui proses rantai makanan. Merkuri dalam tanah akan diserap oleh tumbuhan dan selanjutnya terjadi proses biomagnifikasi [19]. Kontaminasi logam berat dalam tanah, salah satunya merkuri dapat diatasi dengan proses remediasi baik secara biologis, kimiawi, ataupun fisik.

Salah satu teknik remediasi yang dapat diaplikasikan yaitu teknik remediasi fisik dengan metode stabilisasi-solidifikasi (S/S). Teknologi S/S ini sering diaplikasikan di Amerika Serikat oleh US EPA dalam upaya remediasi lahan tercemar limbah B3 [17]. Secara umum, teknologi S/S merupakan proses enkapsulasi limbah menjadi material yang padat dengan permeabilitas rendah dan mencegah terjadinya migrasi kontaminan dengan memperkecil luas permukaan penyebaran lindi [15].

Pada proses S/S digunakan pengikat (binding agent) anorganik secara umum antara lain: semen portland, pozzolan, dan campuran keduanya [16]. Pozzolan adalah bahan yang mengandung silika atau bahan alumina yang mempunyai sifat seperti semen [16]. Semen portland merupakan perekat hidrolik yang bereaksi dengan air untuk mengikat benda padat lainnya membentuk satu kesatuan massa padat dan keras [6]. Meskipun semen portland memiliki kemampuan mengikat kontaminan yang baik dalam mekanisme solidifikasi, penggunaan semen sebagai binding agent perlu dibatasi. Ditinjau dari aspek teknis, semen portland kurang baik dalam mekanisme stabilisasi kontaminan meskipun memiliki kemampuan sangat baik dalam proses solidifikasi. Oleh karena itu, untuk mengurangi penggunaan dan meningkatkan performa semen portland dalam proses $\mathrm{S} / \mathrm{S}$, ditambahkan 
bahan aditif lain yang juga berperan sebagai binding agent atupun stabilizing agent yang dikenal sebagai pozzolana.

Salah satu pozzolana yang digunakan dalam proses S/S adalah tanah tras yang dapat meningkatkan kekuatan mekanis produk. Pozzolana juga mampu mengisolasi logam berat yang terkandung di dalamnya [1]. Hasil studi menunjukkan bahwa tanah tras berpotensi dijadikan sebagai campuran mortar dengan indikasi hasil positif pada kekuatan serta durabilitas beton yang dihasilkan. Penambahan tanah tras $50 \%$ pada campuran semen portland - tanah tras dalam waktu curing 28 hari memberikan kenaikan hasil uji kuat tekan beton yang dihasilkan sebesar 1,6\% [6]. Oleh sebab itu, diperlukan penelitian lebih lanjut guna mengetahui komposisi optimum campuran semen portland dan tanah tras serta penambahan tanah tercemar merkuri dalam aplikasi teknologi S/S lahan tambang emas rakyat di Kulon Progo, Yogyakarta.

\section{METODE PENELITIAN}

Adapun tahapan penelitian ini dilakukan antara lain:

1) Proses Sampling Tanah Tercemar

Kegiatan sampling dilakukan di lokasi kegiatan tambang emas rakyat Desa Sangon Kulon Progo Yogyakarta. Kegiatan ini diawali dengan survei lokasi untuk menentukan titik-titik pengambilan sampel berdasarkan kontur dan arah aliran air pada lokasi penelitian. Tahapan kegiatan sampling tanah adalah sebagai berikut:

a) Penentuan Titik Sampling

Jumlah titik sampling tanah tercemar ditentukan sebanyak 5 titik dengan masing-masing 1 titik sampling pada tiap lokasi kegiatan tambang emas. Titik kontrol diambil pada lokasi dengan elevasi tertinggi sebanyak 2 buah. Penentuan jumlah titik sampling representatif adalah $20 \%$ dari seluruh populasi sampel, yakni total jumlah lokasi tambang emas di Desa Kokap, Kulonprogo, Yogyakarta sebanyak 10-15 buah tambang [11].

b) Metode Sampling Tanah Tercemar

Kegiatan sampling tanah dilakukan dengan metode zig-zag pada lapisan top soil tanah, yakni pada kedalaman $30 \mathrm{~cm}$ dari permukaan tanah [19]. Titik sampling ditentukan berdasarkan lokasi tambang dengan radius luasan sebesar $100 \mathrm{~m}^{2}$. Pengambilan sampel dilakukan dengan cara menggali tanah pada titik yang telah ditentukan menggunakan peralatan bor tangan.

c) Perlakuan Hasil Sampling

Sampel tanah tercemar dari 5 titik tersebut kemudian dicampur menjadi 1 buah sampel komposit tanah tercemar. Begitu juga dengan sampel tanah kontrol, tanah dari dua titik sampel dicampur menjadi sebuah sampel tanah kontrol. Sampel ditempatkan pada wadah dengan bahan PE yang tidak bereaksi dengan merkuri. Wadah ditutup rapat agar udara tidak masuk serta meminimalisasi terjadinya kontaminasi.

Selanjutnya dilakukan pengujian karakteristik kimia dan fisik sampel tanah. Karakteristik kimia yang diuji yakni kandungan merkuri dalam tanah, $\mathrm{pH}$, serta kadar air tanah. Kadar merkuri tanah diuji menggunakan alat mercury analyzer di Laboratorium Penelitian dan Pengujian Terpadu (LPPT) Universitas Gadjah Mada Yogyakarta.
2) Persiapan Alat dan Bahan

Alat yang digunakan dalam penelitian ini adalah:

a) Alat bor tanah, cangkul, dan kontainer PE dengan penutup.

b) $\mathrm{pH}$ meter

c) Alat uji kadar air yaitu oven $105^{\circ}$, neraca analitik, dan desikator.

d) Alat vicat untuk menguji kebutuhan air pada adonan semen

e) Cetakan kubus yang terbuat dari baja dengan ukuran sisi 5 $\mathrm{cm}$ dan mixer pasta.

f) Alat uji kuat tekan Tourse Universal Testing Machine Type RAT-200. MFG No. 20380 CAP.200 tf.

g) Peralatan uji TCLP yaitu $\mathrm{pH}$ meter tipe BP 3001, pipet ukur, Rotary agitator Model SQ 192, kertas saring Whatman.

Bahan yang digunakan dalam penelitian ini adalah:

a) Tanah tras

b) Semen portland tipe 1 (OPC)

c) Tanah tercemar merkuri

d) Aquades

3) Pelaksanaan Penelitian

Pelaksanaan penelitian dibagi ke dalam 2 tahap, yaitu:

a) Penelitian Tahap I

Pada tahap ini dilakukan variasi terhadap penggunaan semen portland sebagai binding agent dengan campuran tanah tras. Hasil dari penelitian pendahuluan ini adalah komposisi optimum campuran semen portland dan tanah tras. Variabel penelitian tahap I ditampilkan pada Tabel 1.

\begin{tabular}{ccc}
\multicolumn{3}{c}{ Tabel 1 } \\
& Variabel Penelitian Tahap I \\
\hline \hline Benda Uji & $\begin{array}{c}\text { Semen } \\
\text { Portland } \\
(\%)\end{array}$ & Tanah Tras (\%) \\
& 100 & \\
\hline I & 90 & 0 \\
II & 80 & 10 \\
III & 70 & 30 \\
IV & 60 & 40 \\
V & 50 & 50 \\
VI & 40 & 60 \\
VII & 30 & 70 \\
VIII & 20 & 80 \\
IX & 10 & 90 \\
X & & \\
\hline \hline
\end{tabular}

b) Penelitian Tahap II

Variasi yang digunakan yaitu campuran pozzolana optimum yang telah didapatkan dari penelitian tahap 1 dengan penambahan tanah tercemar merkuri. Tahap ini dilakukan untuk tujuan mengetahui persentase optimum tanah tercemar yang bisa ditambahkan ke dalam campuran semen dan tanah tras. Variabel penelitian tahap II pada Tabel 2.

4) Pembuatan Benda Uji

Benda uji pada penelitian tahap I dibuat dengan mencampurkan tanah tras dalam adonan semen. Pembuatan benda uji dilakukan melalui beberapa tahap mulai dari persiapan sampel tanah serta uji konsistensi untuk menentukan kebutuhan air. 
Tabel 2

Variabel Penelitian Tahap II

\begin{tabular}{ccc}
\hline \hline Benda Uji & $\begin{array}{c}\text { Komposisi } \\
\text { Optimum Binder } \\
\text { Tahap I } \\
(\%)\end{array}$ & $\begin{array}{c}\text { Tanah Tercemar } \\
\text { Merkuri (\%) }\end{array}$ \\
\hline I & 50 & 50 \\
II & 40 & 60 \\
III & 30 & 70 \\
IV & 20 & 80 \\
V & 10 & 90 \\
\hline \hline
\end{tabular}

a) Persiapan Sampel Tanah

Persiapan diawali dengan memanaskan tanah tras pada oven $105^{\circ}$ selama 24 jam. Kegiatan ini dimaksudkan untuk menghilangkan kadar air dalam tras agar tidak mengganggu proses penggilingan. Selanjutnya, tras didiamkan pada suhu ruang kemudian digiling dengan alat bond ball mill dengan kecepatan $56 \mathrm{rpm}$ selama \pm 3 jam. Selanjutnya tras diayak menggunakan ayakan $300 \mu \mathrm{m}$ dengan tujuan menyamakan ukuran partikel.

b) Uji Konsistensi Normal

Uji konsistensi normal bertujuan untuk mengetahui kebutuhan air dalam suatu campuran mortar. Uji ini dilakukan menggunakan alat yang dikenal dengan nama vicat. Konsistensi normal tercapai saat batang vicat yang diletakkan di atas permukaan mortar mengalami penurunan sedalam 10 mm dalam waktu 30 detik. Pada keadaan konsistensi normal, air pada mortar telah merata dari satu ujung bagian hingga ujung lainnya. Uji konsistensi normal mengacu pada ASTM C187-11 tentang Standard Test Method for Amount of Water Required for Normal Consistency of Hydraulic Cement Paste.

Uji konsistensi normal dilakukan dengan memperkirakan jumlah air (aquades) yang ditambahkan pada campuran semen portland dan tanah tras. Sebagai acuan awal dalam penentuan volume air yang ditambahkan adalah minimum 35\% dari massa semen [12].

Setelah didapatkan jumlah kebutuhan air, selanjutnya dibuat benda uji menggunakan cetakan specimen mould berbentuk kubus dengan ukuran $5 \mathrm{~cm} \times 5 \mathrm{~cm} \times 5 \mathrm{~cm}$. Massa masingmasing benda uji adalah $300 \mathrm{~g}$. Benda uji yang dibuat pada tahap I sebanyak 10 buah dengan dua kali pengulangan. Pada tahap II dibuat benda uji sebanyak enam buah dengan dua kali pengulangan. Total benda uji yang dibuat adalah 32 buah.

c) Perawatan Mortar (Curing)

Perawatan mortar dilakukan dengan cara menjaga mortar agar tetap lembab untuk mencegah terjadinya retak pada benda uji. Mortar diletakkan pada suhu ruang selama 28 hari. Pada penelitian ini dilakukan moisture curing, yaitu dengan cara meletakkan benda uji di sekitar ember berisi air dan selanjutnya ditutup menggunakan bak besar. Perlakuan ini bertujuan untuk meminimalisasi peluluhan logam berat yang terkandung di dalam mortar semen-tras.

\section{ANALISIS DATA DAN PEMBAHASAN}

\section{A. Karakteristik Sampel Tanah}

1) Karakteristik Fisik Sampel Tanah

Secara fisik sampel tanah lokasi tambang di Desa Kokap, Kulonprogo, Yogyakarta seperti pada Gambar 1. berwarna coklat kekuningan, didominasi oleh lempung, dan basah.

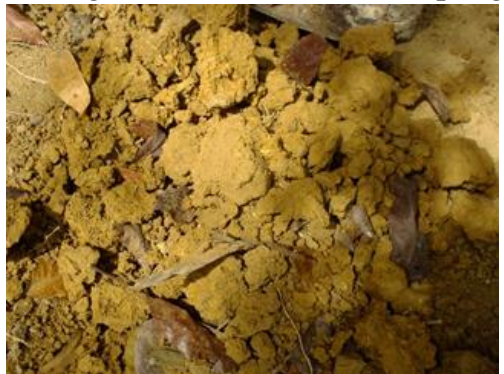

Gambar 1. Karakteristik Fisik Sampel Tanah

Karakterisasi fisik tanah berdasarkan analisis pembagian butir yang mengacu pada ASTM D422 - Standard Test Method for Particle-Size Analysis of Soils yang dilakukan di Laboratorium Mekanika Tanah dan Batuan Teknik Sipil, FTSP ITS ditampilkan pada Tabel 3.

Tabel 3

Hasil Analisis Pembagian Butir Sampel Tanah

\begin{tabular}{lcc}
\hline \hline Jenis Butiran & $\begin{array}{c}\text { Ukuran Partikel } \\
(\mathbf{m m})\end{array}$ & Kandungan (\%) \\
Kerikil & $\geq 4,76$ & 1,86 \\
Pasir & & 55,17 \\
$\quad$ - Kasar & $\geq 2,00$ & \\
$\quad-\quad$ Medium & $\geq 0,425$ & \\
$\quad-\quad$ Halus & $\geq 0,075$ & \\
Lanau & $\geq 0,0055$ & 30,69 \\
Lempung & $\geq 0,0001$ & 12,27 \\
\hline \hline
\end{tabular}

\section{2) Karakteristik Kimia Sampel Tanah}

Karakterisasi kimia sampel tanah meliputi: $\mathrm{pH}$, kadar air, serta konsentrasi total merkuri. Sampel tanah teridentifikasi memiliki nilai ph relatif netral yakni 6,78 . Nilai kadar air pada sampel tanah adalah sebesar $13,24 \%$. Nilai tersebut sesuai dengan karakter top soil pada umumnya yakni $\mathrm{pH}$ tanah netral hingga basa berkisar antara 6-8 [9].

Analisis total merkuri pada sampel tanah dilakukan di Laboratorium Penelitian dan Pengujian Terpadu (LPPT) Universitas Gadjah Mada Yogyakarta. Hasil uji kadar total merkuri pada sampel tanah kontrol yakni sebesar $79,14 \mu \mathrm{g} / \mathrm{kg}$ atau setara dengan $0,079 \mathrm{mg} / \mathrm{kg}$. Hasil uji kadar total merkuri pada sampel tanah tercemar sekitar sepuluh kali lipat lebih besar dari tanah kontrol yakni $892,53 \mu \mathrm{g} / \mathrm{kg}$ atau setara dengan $0,89 \mathrm{mg} / \mathrm{kg}$. Merkuri merupakan salah satu logam berat yang memiliki sifat toksik terhadap manusia serta organisme lainnya [2]. Berdasarkan PP 101/2014 nilai baku mutu karakteristik beracun melalui TCLP dan total konsentrasi untuk penetapan pengelolaan tanah terkontaminasi limbah B3 adalah total konsentrasi A (TK-A) $300 \mathrm{mg} / \mathrm{kg}$, TK-B sebesar 
$75 \mathrm{mg} / \mathrm{kg}$, dan TK-C $0,3 \mathrm{mg} / \mathrm{kg}$. Dilihat dari baku mutu tersebut, tanah tambang emas Kulon Progo, Yogyakarta melebihi baku mutu TK-C sehingga dapat dikatakan tanah tersebut tercemar merkuri dari proses tambang emas.

\section{B. Penelitian Tahap I}

1) Kebutuhan Air dari Hasil Uji Konsistensi Normal Hasil uji konsistensi tahap I disajikan pada Gambar 2.

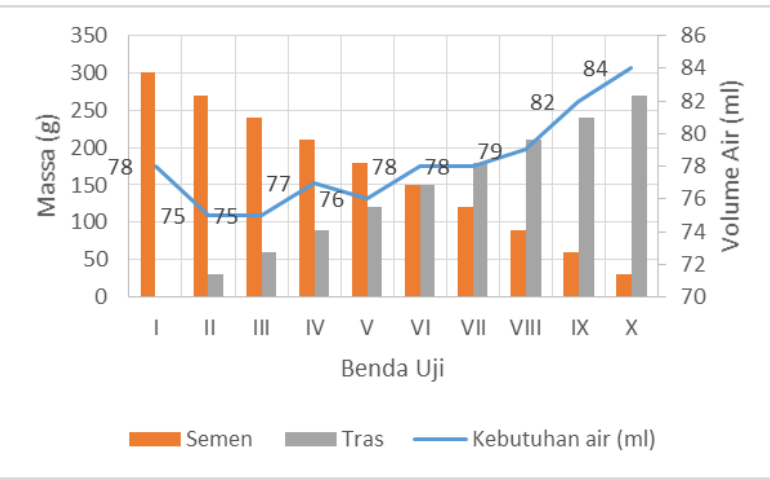

Gambar 2. Grafik Kebutuhan Air Konsistensi Tahap I

Berdasarkan hasil uji konsistensi normal, dapat dilihat bahwa dengan semakin banyaknya penambahan tras ke dalam campuran semen kebutuhan air cenderung semakin meningkat. Pada kadar semen $100 \%$ volume kebutuhan air adalah $78 \mathrm{ml}$. Selanjutnya kebutuhan air menurun menjadi $75 \mathrm{ml}$ ketika ditambahkan $10 \%$ dan $20 \%$ tras. Penurunan volume kebutuhan air ini disebabkan karena reaksi hidrasi yang tertahan. Reaksi tersebut terjadi pada awal penambahan air menghasilkan endapan $\mathrm{Ca}(\mathrm{OH})_{2}$, etteringite, dan $\mathrm{C}-\mathrm{S}-\mathrm{H}$ yang membentuk coating pada partikel semen [6]. Selanjutnya kebutuhan air cenderung naik dengan penambahan tras. Tanah tras terdiri dari senyawa silika-alumina reaktif yang mampu bereaksi dengan air membentuk material baru sebagai kesatuan massa yang padat [5]. Hal tersebut terjadi akibat adanya reaksi pozzolanic antara tras-semen dan air [6]. Reaksi pozzolanic yang terjadi adalah

$2 \mathrm{Al}_{2} \mathrm{O}_{3} \cdot 2 \mathrm{SiO}_{2}+7 \mathrm{Ca}(\mathrm{OH})_{2} \rightarrow 3 \mathrm{CaO} \cdot 2 \mathrm{SiO}_{2} \cdot \mathrm{H}_{2} \mathrm{O}+$ $2\left(2 \mathrm{CaO} \cdot \mathrm{Al}_{2} \mathrm{O}_{3} \cdot \mathrm{SiO}_{2} \cdot 2 \mathrm{H}_{2} \mathrm{O}\right)$

2) Hasil Uji Kuat Tekan I

Kuat tekan dihitung dengan persamaan :

\begin{tabular}{|c|c|c|c|c|}
\hline \multicolumn{5}{|c|}{ Kuat Tekan $\left(\mathrm{kg} / \mathrm{cm}^{2}\right)=$} \\
\hline \multicolumn{5}{|c|}{$\begin{array}{c}\text { Tabel } 4 \\
\text { Hasil Uji Kuat Tekan Tahap I } \\
\end{array}$} \\
\hline Nama & Bebal & ekan & Beban & Kuat \\
\hline Benda & & & Tekan & Tekan \\
\hline Uji & A & B & $\begin{array}{l}\text { Rata-rata } \\
(\mathrm{kg})\end{array}$ & $\left(\mathrm{kg} / \mathrm{cm}^{2}\right)$ \\
\hline I & 12350 & 12000 & 12175 & 487 \\
\hline II & 10750 & 8800 & 9775 & 391 \\
\hline III & 10900 & 9600 & 10250 & 410 \\
\hline IV & 9150 & 11000 & 10075 & 403 \\
\hline V & 6550 & 9200 & 7875 & 315 \\
\hline VI & 7550 & 8000 & 7775 & 311 \\
\hline VII & 6500 & 4600 & 5550 & 222 \\
\hline VIII & 4900 & 5400 & 5150 & 206 \\
\hline IX & 3550 & 5000 & 4275 & 171 \\
\hline$X$ & 1800 & 3000 & 2400 & 96 \\
\hline
\end{tabular}

Hasil kuat tekan tahap I ditampilkan pada Tabel 4.

Nilai kuat tekan tertinggi pada benda uji I dengan kandungan semen $100 \%$. Selanjutnya nilai kuat tekan relatif menurun dengan pengurangan semen. Akan tetapi pada benda uji III terjadi peningkatan nilai kuat tekan sebesar $19 \mathrm{~kg} / \mathrm{cm}^{2}$ dari benda uji II. Menurut [20] faktor-faktor yang mempengaruhi kuat tekan beton antara lain: pasta semen, volume rongga, agregat, dan interface (hubungan antar muka) antara pasta semen dengan agregat. Selain itu, faktor lain yang mempengaruhi kuat tekan adalah faktor teknis, yaitu proses pencetakan dan pemadatan secara manual yang tidak sempurna (Faisal, 2015). Kenaikan kuat tekan dapat terjadi karena adanya proses hidrasi serta hubungan antar muka antara pasta semen dengan agregat yang baik.

Kuat tekan merupakan salah satu parameter untuk mengukur keberhasilan proses solidifikasi. Dilihat dari parameter nilai kuat tekan, seluruh benda uji memenuhi ketentuan baku mutu US EPA untuk pengelolaan tanah tercemar yakni sebesar $3,5 \mathrm{~kg} / \mathrm{cm}^{2}$. Penentuan komposisi optimum dilihat dari penggunaan semen yang paling sedikit dengan pertimbangan sisi ekonomis sehingga teknologi S/S ini dapat diaplikasikan. Dengan pertimbangan tersebut, ditetapkan komposisi optimum campuran semen-tras yakni pada variasi campuran $10: 90$.

\section{Penelitian Tahap II}

1) Kebutuhan Air Uji Konsistensi Normal

Uji konsistensi normal tahap II dilakukan untuk mengetahui kebutuhan air pada campuran semen-tras dengan penambahan tanah. Hasil uji konsistensi disajikan pada Gambar 3.

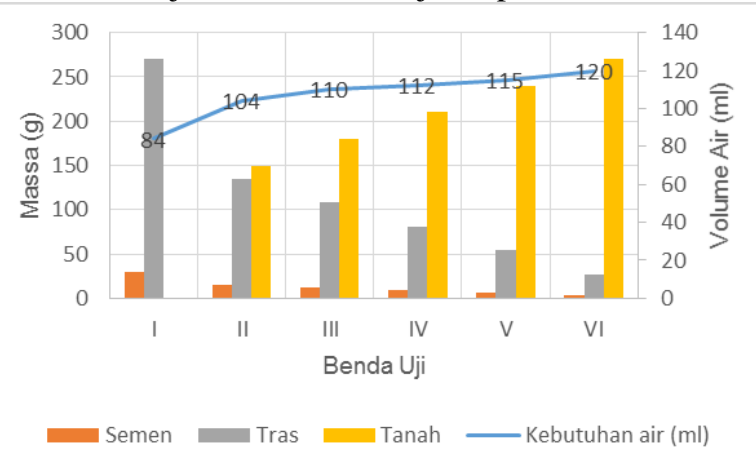

Gambar 3. Grafik Kebutuhan Air Konsistensi Tahap II

Kebutuhan air meningkat seiring dengan penambahan tanah tercemar. Peningkatan kebutuhan air akibat penambahan tanah disebabkan karena sampel tanah dengan sifat fisik berupa lempung lanau cenderung menahan air. Menurut [6], tanah bertekstur lempung mempunyai luas permukaan spesifik yang luas sehingga memiliki kemampuan mengikat air yang tinggi. Saat air terikat oleh partikel lempung, akan terjadi lekatan yang kuat, sehingga air dapat tertahan di dalam partikel lempung. Hal tersebut terlihat jelas pada benda uji II yang mengalami peningkatan kebutuhan air dibandingkan benda uji I yakni dari $84 \mathrm{ml}$ menjadi $104 \mathrm{ml}$ dengan penambahan $50 \%$ sampel tanah tercemar.

2) Hasil Uji Kuat Tekan II

Hasil uji kuat tekan II ditampilkan pada Tabel 5. Hasil kuat tekan tertinggi pada benda uji I yakni sebesar $96 \mathrm{~kg} / \mathrm{cm}^{2}$ tanpa 
penambahan tanah tercemar. Selanjutnya nilai kuat tekan mengalami penurunan dengan penambahan tanah tercemar.

Tabel 5

Hasil Uji Kuat Tekan Tahap II

\begin{tabular}{ccccc}
\hline \hline $\begin{array}{c}\text { Benda } \\
\text { Uji }\end{array}$ & \multicolumn{2}{c}{ Beban Tekan (kg) } & $\begin{array}{c}\text { Beban } \\
\text { Tekan Rata- } \\
\text { rata }(\mathrm{kg})\end{array}$ & $\begin{array}{c}\text { Kuat } \\
\text { Tekan } \\
\left(\mathrm{kg} / \mathrm{cm}^{2}\right)\end{array}$ \\
I & 1800 & 3000 & 2400 & 96,0 \\
II & 820 & 1040 & 930 & 37,2 \\
III & 560 & 520 & 540 & 21,6 \\
IV & 300 & 300 & 300 & 12,0 \\
V & 320 & 160 & 240 & 9,6 \\
VI & 140 & 160 & 150 & 6,0 \\
\hline \hline
\end{tabular}

Hal tersebut dapat terjadi karena berkurangnya kadar binder yang berperan sebagai perekat campuran. Hasil kuat tekan terkecil pada benda uji VI dengan komposisi binder : tanah (10 : 90) yakni sebesar $6 \mathrm{~kg} / \mathrm{cm}^{2}$. Nilai tersebut masih memenuhi baku mutu kuat tekan produk S/S menurut US EPA sebesar $3,5 \mathrm{~kg} / \mathrm{cm}^{2}$.

\section{3) Uji TCLP}

Uji TCLP dilakukan mengacu pada US EPA Method 1311 yang merupakan parameter efektivitas proses stabilisasi. Uji TCLP merupakan salah satu persyaratan uji untuk menentukan tingkat toksik limbah B3 menurut PP 101/2014. TCLP dilakukan dengan menghancurkan benda uji kemudian diekstrak menggunakan larutan ekstraksi sesuai dengan $\mathrm{pH}$ sampel. Penentuan penggunaan larutan ekstraksi dilakukan dengan mengukur $\mathrm{pH}$ awal sampel dan $\mathrm{pH}$ akhir sampel. Pada pengukuran awal sampel, benda uji dihancurkan dan ditambahkan aquades. Apabila $\mathrm{pH}$ sampel terukur lebih besar dari 5 maka ditambahkan $\mathrm{HCl} 1 \mathrm{~N}$ ke dalamnya dan diukur kembali $\mathrm{pH}$ sampel sebagai $\mathrm{pH}$ akhir.

Proses TCLP merupakan simulasi produk S/S terhadap kondisi lingkungan asli di lokasi remediasi [13]. Tanah di lokasi remediasi memiliki kandungan asam-asam organik yang berpotensi menyebabkan peluluhan logam berat yang telah diikat oleh binder pada proses S/S. Oleh sebab itu, proses ekstraksi TCLP dilakukan menggunakan larutan buffer asam asetat dengan $\mathrm{pH} \pm 5$. Adapun hasil pengukuran $\mathrm{pH}$ awal dan akhir sampel ditampilkan pada Tabel 6.

Tabel 8

Hasil Uji Kuat Tekan Tahap II

\begin{tabular}{cccc}
\hline \hline Benda Uji & $\begin{array}{c}\text { Komposisi } \\
\text { Binder : Tanah }\end{array}$ & pH awal & $\begin{array}{c}\mathrm{pH} \\
\text { akhir }\end{array}$ \\
I & $100: 0$ & 11,10 & 4,50 \\
II & $50: 50$ & 10,50 & 4,00 \\
III & $40: 60$ & 10,40 & 3,70 \\
IV & $30: 70$ & 10,20 & 2,76 \\
V & $20: 80$ & 10,10 & 2,62 \\
VI & $10: 90$ & 10,10 & 1,64 \\
\hline \hline
\end{tabular}

Dari hasil Tabel 6 semua sampel memiliki pH kurang dari 5 sehingga untuk proses agitasi digunakan larutan ekstraksi 1. Perbedaan nilai $\mathrm{pH}$ pada sampel terjadi akibat perbedaan jumlah binder yang ditambahkan. Binder merupakan campuran semen-tras yang terdiri dari senyawa dominan $\mathrm{CaO}$, $\mathrm{SiO}_{2}$ dan $\mathrm{Al}_{2} \mathrm{O}_{3}$ yang bersifat basa [5]. Oleh sebab itu, pengurangan binder berakibat pada pengurangan $\mathrm{pH}$ benda uji.

Selanjutnya dilakukan pengukuran kadar merkuri di Laboratorium Center of Drug Evaluation and Analysis Universitas Surabaya menggunakan metode uji Inductively Coupled Plasma Atomic Emission Spectroscopy (ICP-AES).

Tabel 6

Hasil Uji Kadar Merkuri Metode ICP-AES

\begin{tabular}{|c|c|c|c|}
\hline $\begin{array}{l}\text { Benda } \\
\text { Uji }\end{array}$ & $\begin{array}{c}\text { Komposisi } \\
\text { Binder : } \\
\text { Tanah }\end{array}$ & $\begin{array}{c}\text { Konsentrasi } \\
\text { Merkuri (mg/l) }\end{array}$ & Keterangan \\
\hline I & $100: 0$ & Tidak Terdeteksi & Limit of \\
\hline II & $50: 50$ & Tidak Terdeteksi & Detection \\
\hline III & $40: 60$ & Tidak Terdeteksi & (LOD) \\
\hline IV & $30: 70$ & Tidak Terdeteksi & $0,210 \mathrm{ppm}$ \\
\hline V & $20: 80$ & Tidak Terdeteksi & \\
\hline VI & $10: 90$ & Tidak Terdeteksi & \\
\hline
\end{tabular}

Hasil pengujian kadar merkuri ditampilkan pada Tabel 7.

Berdasarkan Tabel 7 seluruh benda uji tidak terdeteksi adanya merkuri. Diketahui bahwa LOD alat yang digunakan adalah 0,210 ppm. Hasil merkuri yang tidak terdeteksi diprediksi karena konsentrasi merkuri dalam benda uji sangat kecil di bawah LOD alat yang digunakan. Oleh sebab itu, dilakukan pengujian Ka adar merkuri ulang dengan metode uji Atomic Absorbtion Spectrofotometry (AAS) 2011 di Laboratorium Pengujian dan Kalibrasi BARISTAND Industri Surabaya. Kandungan $\mathrm{Hg}^{2+}$ pada larutan ekstraksi TCLP akan direduksi oleh $\mathrm{Sn}^{2+}$ menjadi $\mathrm{Hg}$. Atom $\mathrm{Hg}$ itulah yang terbaca secara kuantitatif pada spektrofotometer [3]. Hasil uji kadar Tabel 7

Hasil Uji Kadar Merkuri Metode AAS

\begin{tabular}{ccc}
\hline \hline Benda & Komposisi Binder: & Konsentrasi Merkuri (mg/l) \\
Uji & Tanah & Tidak Terdeteksi \\
I & $100: 0$ & 0,0009 \\
II & $50: 50$ & 0,0007 \\
III & $40: 60$ & 0,0009 \\
IV & $30: 70$ & 0,0011 \\
V & $20: 80$ & 0,0011 \\
VI & $10: 90$ & \\
\hline
\end{tabular}

merkuri sampel ditampilkan pada Tabel 8 .

Dari Tabel 8 konsentrasi merkuri mengalami peningkatan dengan penambahan tanah tercemar. Pada benda uji I dengan kadar binder $100 \%$ tidak terdeteksi adanya merkuri di dalamnya. Dengan demikian binder berupa campuran trassemen tidak ada kontaminasi merkuri. Konsentrasi merkuri berfluktuasi pada benda uji II, III, dan IV serta mengalami peningkatan pada benda uji V dan VI. Akan tetapi fluktuasi dan peningkatan yang terjadi tidak signifikan. Hal itu terjadi karena mobilitas merkuri yang rendah pada $\mathrm{pH}$ tinggi.

Nilai konsentrasi merkuri pada tiap benda uji merupakan parameter efektivitas proses stabilisasi yang terjadi. Selain proses stabilisasi, nilai merkuri pada benda uji juga memiliki 
korelasi dengan proses solidifikasi . Hal tersebut dapat dilihat pada Gambar 4.

Berdasarkan Gambar 4, konsentrasi merkuri relatif meningkat dengan penurunan kuat tekan benda uji. Hal itu terjadi karena semakin sedikit binder yang digunakan semakin kecil pula nilai kuat tekan benda uji sehingga merkuri tidak dapat diikat dengan sempurna. Pada benda uji 3 terjadi penurunan konsentrasi merkuri dibandingkan dengan benda uji 2 dengan komposisi binder yang lebih besar. Hal tersebut diakibatkan karena teknis pembuatan benda uji secara manual, yaitu pada proses pemadatan dan perataan dalam cetakan spesimen mould. Akibatnya campuran agregat tanah dan binder tidak merata.

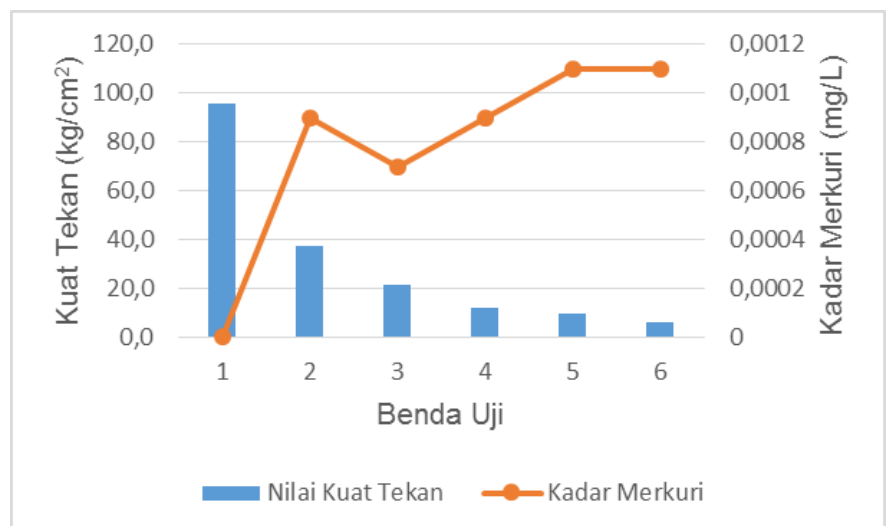

Gambar 4. Grafik Hubungan Kuat Tekan dan Konsentrasi Merkuri

Salah satu faktor yang mempengaruhi kekuatan mortar yang ditunjukkan oleh suatu nilai kuat tekan adalah interface (hubungan antar muka) pasta semen dan agregat (Widodo, 2010). Berkurangnya nilai kuat tekan menunjukkan hubungan antar muka antara binder dan agregat tanah tercemar tidak sempurna. Oleh sebab itu, saat proses ekstraksi TCLP akan terdapat lebih banyak merkuri yang terlindikan.

Penurunan konsentrasi merkuri pada tanah tercemar setelah mengalami proses $\mathrm{S} / \mathrm{S}$ adalah karena adanya proses stabilisasi merkuri dalam semen dan pozzolan. Merkuri akan mengalami proses pengendapan membentuk suatu endapan merah $\mathrm{HgO}$ [21]. Pengendapan terjadi karena adanya reaksi antara $\mathrm{Hg}^{2+}$ dengan senyawa basa dan karbonal dalam semen dan pozzolan. Reaksi yang terjadi dapat ditulis sebagai berikut:

$$
\begin{array}{lll}
\mathrm{Hg}^{2+}+\mathrm{OH}^{-} & \rightarrow & \mathrm{Hg}(\mathrm{OH})_{2} \downarrow \\
\mathrm{Hg}(\mathrm{OH})_{2} & \rightarrow & \mathrm{HgO} \downarrow+\mathrm{H}_{2} \mathrm{O} \\
\mathrm{Hg}^{2+}+\left(\mathrm{CO}_{3}\right)^{2-} & \rightarrow & \mathrm{HgCO}_{3} \downarrow
\end{array}
$$

Struktur kristal yang terbentuk dari proses hidrasi inilah yang mampu mengikat kontaminan logam berat setelah menjadi presipitasi hidroksida dan garam karbonat [14].

Pada benda uji VI dengan kadar tanah tercemar paling banyak yakni $90 \%$ memiliki konsentrasi akhir merkuri 0,0011 $\mathrm{mg} / \mathrm{l}$. Nilai tersebut memenuhi baku mutu kadar merkuri menurut PP No. 101 Tahun 2014 untuk pengelolaan tanah tercemar yakni TCLP-B yakni sebesar 0,02 mg/l. Komposisi optimum dipilih berdasarkan pertimbangan ekonomis dan aplikatif yaitu penambahan tanah tercemar paling banyak dengan konsumsi binder paling sedikit. Dengan beberapa pertimbangan tersebut, komposisi optimum penelitian tahap II yaitu pada variasi komposisi binder : tanah (10:90).

\section{KESIMPULAN}

1) Komposisi optimum binder (semen : tras) dari penelitian tahap I adalah 10 : 90. Penentuan ini didasarkan pada nilai kuat tekan benda uji yakni $96 \mathrm{~kg} / \mathrm{cm}^{2}$.

2) Komposisi optimum binder dan tanah tercemar adalah 10 : 90. Pada komposisi tersebut didapatkan nilai kuat tekan sebesar $6 \mathrm{~kg} / \mathrm{cm}^{2}$ dan total konsentrasi merkuri pada uji TCLP sebesar $0,0011 \mathrm{mg} / \mathrm{l}$.

\section{UCAPAN TERIMA KASIH}

Ucapan terima kasih penulis sampaikan kepada Bapak Ranno Marlany Rachman sebagai penyedia dana penelitian dan rekan penelitian Thaniya Triagustine Kalimantoro serta Zofar Banunaek.

\section{DAFTAR PUSTAKA}

[1] Alina, B., Georgescu, M., dan Zahanagiu, A. 2008. Properties Of Blended Cements With Hazardous Waste Content. Journal of Applied Chemistry and Material Science, 53(3), 229-237.

[2] Alpers, C.N. dan Hunerlach, M.P. 2000. Mercury Contamination from Historic Gold Mining in California. California : US Geologiical Survey.

[3] Badan Standarisasi Nasional. 2011. SNI 2493:2011. Tata Cara Pembuatan dan Perawatan Benda Uji Beton di Laboratorium.

[4] Gunawan, A., Setiawan, L., Subarna, A.W., dan Suhendi, E. 2001. Percontohan Penambangan Emas di Kecamatan Kokap, Kabupaten Kulon Progo, Daerah Istimewa Yogyakarta. Puslitbang Tekmira : Bandung

[5] Indrawati, V. dan Manaf A. 2008. Mechanical Strength of Trass as Supplementary Cementing Material. Journal of Physic Science,19(2), $51-59$.

[6] Intara, Y., Sapei, A., Sembiring, N., dan Djoefrie, M. 2011. Pengaruh Pemberian Bahan Organik pada Tanah Liat dan Lempung Berliat terhadap Kemampuan Mengikat Air. Jurnal Ilmu Pertanian Indonesia, $16,130-135$.

[7] Mudyazhezha, S., dan Kanhukamwe, R. 2014. Environmental Monitoring Of The Effects Of Conventional And Artisanal Gold Mining On Water Quality In Ngwabalozi River, Southern Zimbabwe. Journal of Environmental Monitoring and Analysis, 2, 123-127.

[8] Peraturan Pemerintah Nomor 101 Tahun 2014 Pengelolaan Limbah Bahan Berbahaya dan Beracun. Pemerintah Republik Indonesia.

[9] Rahmawati, I. 2015. Pengaruh Faktor Fisika dan Kimia Tanah terhadap Indeks Keanekaragaman Hewan Tanah. Pendidikan Biologi Universitas Riau.

[10] Rianto, S. 2010. Analisis Faktor - Faktor Yang Berhubungan Dengan Keracunan Merkuri Pada Penambang Emas Tradisional Di Desa Jendi Kecamatan Selogiri Kabupaten Wonogiri. Tesis Magister Kesehatan Lingkungan Universitas Diponogoro, Semarang.

[11] Setiabudi, B.T. 2005. Penyebaran Merkuri Akibat Usaha Pertambangan Emas Di Daerah Sangon, Kabupaten Kulon Progo, D.I. Yogyakarta. Kolokium Hasil Lapangan - Subdit Konservasi DIY.

[12] Suparjo, M. dan Suhana. 2005. Pengaruh Faktor Air Semen Terhadap Komposisi Campuran Beton Ringan Tanpa Pasir dengan Agregat Limbah Batu Apung. http://ejournal.ftunram.ac.id/abstrak.php?id=3\&vol=3\&edisi=1\&idisi=1 44\&baca=1. Diunduh tanggal 30 Juli 2015.

[13] Suyono, A. 2011. Dampak Penggunaan Hg pada Penambangan Emas Rakyat Terhadap Lingkungan. Program Studi Teknik Lingkungan. UPN Veteran Yogyakarta.

[14] Trihadiningrum, Y. 2000. Pengelolaan Limbah Bahan Berbahaya dan Beracun. Jurusan Teknik Lingkungan, FTSP-ITS, Surabaya.

[15] US EPA. 2000. Solidification / Stabilization Use at Superfund Sites. EPA Publication 542-R-00-010, Washington DC, USA.

[16] US EPA. 2006. In Situ Treatment Technologies for Contaminated Soil. EPA Publication 542-F-06-013, Washington DC, USA.

[17] US EPA. 2007. Treatment Technologies for Mercury in Soil, Waste, and Water. Washington DC, USA. 
[18] Veiga, M.M. 2004. Protocols for Environmental and Health Assesment of Mercury Released by Artisanal and Small Scale Miners - Global Mercury Project. Veina International Center : Austria.

[19] Wang, J., Feng, X., Anderson, C., Xing, Y., dan Shang, L. 2012. Remediation of mercury contaminated sites - A review. Journal of Hazardous Materials, 221-222, 1-18.

[20] Widodo, S. 2010. Modul Bahan Bangunan : Bagian Uji Kuat Tekan Beton. http://modul.umy.ac.id/bagiankuattekanbeton.php?. Diakses pada 13 Mei 2016.

[21] Zhang, X., Qi-Cao, W., Shao-Qing, Z., Xiao-Jing, S., Zhong-Sheng, Z. 2009. Stabilization/Solidification (S/S) Of Mercury-Contaminated Hazardous Wastes Using Thiol-Functionalized Zeolite And Portland Cement. Journal of Hazardous Materials, 168, 1575-1580. 